\title{
Die „Handtaschenzystoskopie“ zu Demonstrationszwecken
}

\author{
Bei Abteilungsführungen oder im Unterricht kann eine Zystoskopie selten direkt am Patienten \\ demonstriert werden. Doch wie lässt sich die Untersuchung trotzdem anschaulich erklären? \\ Unser Autor verrät es Ihnen.
}

In Zeiten modernen Medizinmarketings gehören Abteilungsführungen, „Tage der offenen Tür“" oder die Beteiligung an Seniorenmessen, Gesundheitstagen und ähnlichen Aktionen zum Alltag in der Urologie in Klinik und Praxis. Aber auch im Schwesternunterricht, PJ-Seminaren oder bei der Führung von Besuchergruppen besteht die Notwendigkeit, nicht nur die Möglichkeiten moderner endourologischer Diagnostik zu demonstrieren, sondern auch Begeisterung für das Fach gerade bei jungen Menschen zu wecken. Wie jedoch kann plastisch verdeutlicht werden, wie eine Zystoskopie funktioniert? Wie Licht in die Blase kommt? Wie „um die Ecke geschaut“ wird? Da in diesem Setting nur selten am Patienten demonstriert werden kann, bietet die „Handtaschenzystoskopie“ eine elegante Lösung.

Ein nur mit Kaltlicht ausgestattetes flexibles Videozystoskop wird dazu benutzt, in eine (geschlossene) Handtasche einer der Besucherinnen zu schauen (o Abb.1). Es kommen Haarbürsten, Geldbörsen, Schlüsselbünde und andere Überraschungen zur (übergroßen) Darstellung (○ Abb.2), Interessierten kann das Instrument gefahrlos übergeben werden - meist wird der Unterschied zu einem erfahrenen Endoskopeur sofort spürbar. Humorvoll kommentiert kann so ein solcher Event mit der „Handtaschenzystoskopie“ zu einem bleibenden Erlebnis für die Beteiligten werden.

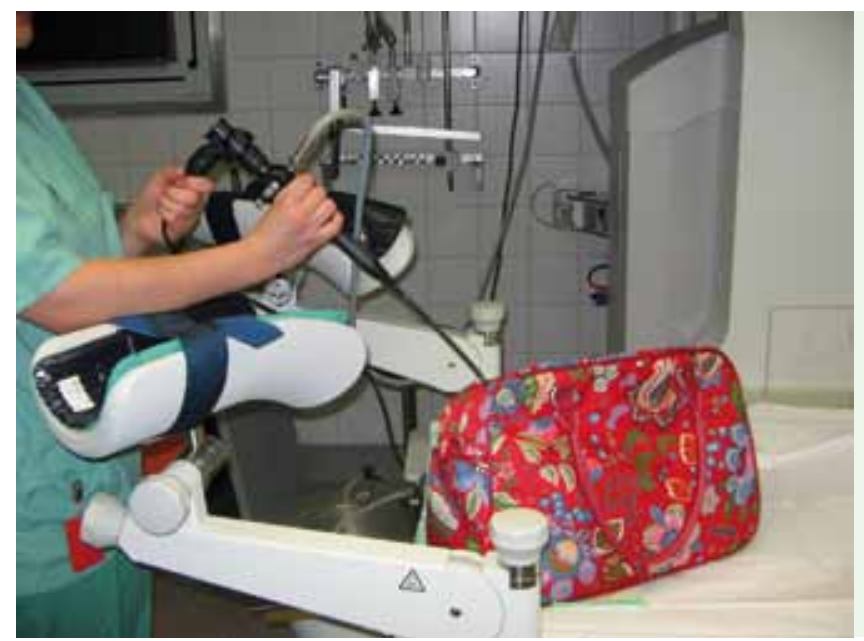

Abb. 1 Einführen des flexiblen Zystoskops in eine Besucher-Handtasche.

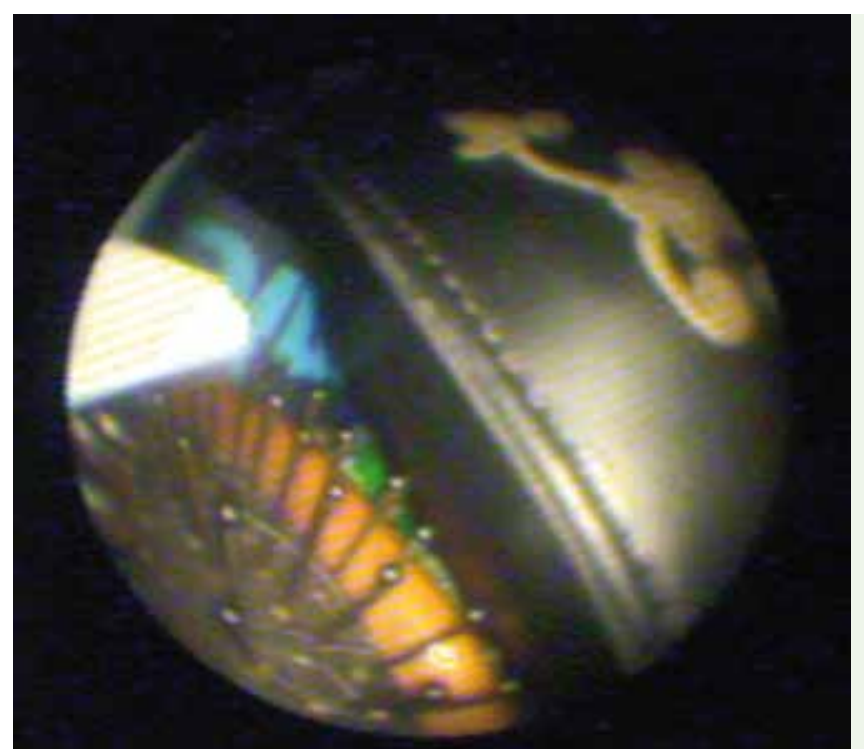

Abb. 2 Haarbürste, Geldbörse.

PD Dr. Andreas Wiedemann

Korrespondenz:

PD Dr. Andreas Wiedemann

Urologische Klinik

Evangelisches Krankenhaus

im Diakoniewerk Ruhr gGmbH

Lehrstuhl für Geriatrie

der Universität Witten/Herdecke

Pferdebachstr. 27

58455 Witten

Tel. 02 302/175-2521

awiedemann@diakonie-ruhr.de 